\title{
Preventable infant mortality: Spatial distribution and main causes in three Brazilian municipalities
}

\author{
Rosana Rosseto de Oliveira ${ }^{1}$, Thais Aidar de Freitas Mathias ${ }^{2}$ \\ ${ }^{1}$ Graduate Nursing Program, State University of Maringá, Maringá, Brazil; rosanarosseto@gmail.com \\ ${ }^{2}$ Nursing Department, Graduate Nursing Program, State University of Maringá, Maringá, Brazil; tafmathias@uem.br
}

Received 29 May 2013; revised 28 June 2013; accepted 15 July 2013

Copyright (C) 2013 Rosana Rosseto de Oliveira, Thais Aidar de Freitas Mathias. This is an open access article distributed under the Creative Commons Attribution License, which permits unrestricted use, distribution, and reproduction in any medium, provided the original work is properly cited.

\begin{abstract}
Objective: The objective was to identify spatial distribution patterns for preventable infant mortality and the main causes of death in three municipalities of Paraná state, Brazil. Design and Sample: Ecological study on infant mortality among residents of the municipalities of Maringá, Sarandi and Paiçandu, between 2004 and 2008. Measures: Data were obtained from reports by the Infant Mortality Prevention Committee, georeferenced in 19 Demographic Expansion Areas and analyzed statistically using Local Moran's Index. Results: Of the 284 deaths among children under one year of age, $68.7 \%$ were considered preventable, and higher percentages were found in outlying areas. The main causes were illnesses originated during the perinatal period $(73.8 \%)$, external causes $(11.3 \%)$ and diseases of the respiratory system (5.1\%). Conclusion: It is necessary to implement actions and policies on child and prenatal assistance, in order to reduce the inequality observed between the central and outlying areas of the region under study.
\end{abstract}

Keywords: Infant Health; Mortality; Public Health; Population-Based Nursing

\section{INTRODUCTION}

Infant mortality is an indicator of quality of life and health, reflects socioeconomic conditions and is also a parameter to evaluate the organization and quality of health services and obstetric and neonatal assistance [1]. Knowing the context in which child deaths occur is essential to evaluating local actions with regard to women's and children's health, as well as to promoting measures against potentially preventable infant morbimortality [2].

Preventable causes of child mortality are defined as events, fully or partially preventable by effective actions from health services accessible at a given place and time. Thus, by using the full set of technology resources and updated health knowledge, these events should not occur. The causes of preventable death are sensitive to health care, but they also respond significantly to improve living conditions, access to goods and services, schooling and income [3].

The precursor of the debate on the term preventability was David Rutstein, who defined it as a sentinel eventsomething that should not occur, whether preventable illness, unexpected disability or death; its occurrence serves as a warning sign that the quality of therapy or promotion/prevention measures must be better analyzed [4].

A study performed in Brazil and other regions from 1997 to 2006 indicated a $37 \%$ reduction in the rate of infant mortality from preventable causes [3], demonstrating the positive impact of health services in improving living conditions for the population. Nevertheless, infant mortality still reaches high rates-in 2011 it stood at 21.17 deaths per thousand live births, most of which were potentially preventable [5]. In the state of Paraná, a study using results of analyses on child deaths investigated by the Infant Mortality Prevention Committees (IMPC) showed that $55 \%$ of deaths could have been avoided through adequate care during gestation, delivery and the neonatal period [6].

Despite its decline, infant mortality remains a health priority in developing countries given extensive regional inequalities, between and within cities, which justifies the analysis of infant mortality and its preventability on a regional approach. To that end, geoprocessing techniques utilize space as an analytical category and use thematic maps to describe different health phenomena-from the 
distribution of morbi-mortality patterns to the allocation of services [7]. By establishing the location in geographical space where a phenomenon took place, georeferencing contributes to a better understanding of it, making it possible to identify characteristics that reveal the social, economic and environmental structure in which a health event occurs [8].

Considering that infant mortality still is high in some regions of Brazil, that most deaths are considered preventable, and that few studies have shown this problem using georeferencing techniques, the object of this study was to identify patterns of spatial distribution and the main causes of potentially preventable infant mortality in a region of Paraná state, Brazil. The results are expected to contribute to the planning, organization and execution of health actions, and to aid in finding causal explanations for preventable infant mortality, defining priorities for intervention.

\section{METHODS}

\subsection{Design and Sample}

It was an ecological study including all deaths of children under one year of age, investigated by the IMPC of the $15^{\text {th }}$ Regional Health District of the State of Paraná, among residents of the municipalities of Maringá, Sarandi and Paiçandu, between January 1, 2004 and December 31, 2008. Maringá had a population of 357,077 inhabitants in 2010, urbanization rate of 98.2\%, Human Development Index (HDI) of 0.84 for the year 2000 [9], and is located in northwestern Paraná state. Sarandi, a municipality that is conurbated with Maringá to the east, had 82,847 inhabitants in 2010 [9], has the highest population density (799 inhabitants/ $\mathrm{km}^{2}$ ) among the municipalities in this study, urbanization rate of $99.1 \%$ and HDI of 0.76 in 2000, regarded as medium human development. Paiçandu, a municipality conurbated with Maringá to the west, has 35,936 inhabitants, population density of 210.2 inhabitants $/ \mathrm{km}^{2}$, urbanization rate of $98.6 \%$, and HDI of 0.74 [9].

The municipalities were analyzed as a whole, as Maringá, Paiçandu and Sarandi are conurbated, forming a single footprint of urban occupation, with a high degree of socioeconomic and spatial interaction, representing an urban agglomeration [10]. They are engaged in intermunicipal flows of commerce and services, with functional synergy.

\subsection{Measures}

The classification of preventability and the underlining cause of death were collected from the Infant Mortality Investigation System (SIMI), a database containing the main conclusions of the analyses of child deaths undertaken by the IMPC of the $15^{\text {th }}$ Regional Health District of
Maringá. IMPC analyzes the history of each death since gestation, outlining an itinerary up to birth, including admission data for the mother and newborn, establishes the responsibility, prevention measures, preventability, and, when necessary, corrects the underlining cause of death. Data from SIMI and from the Information System on Live Births (SINASC) were combined using the Declaration of Live Birth (LBD) number as the identifying unit.

Demographic Expansion Areas (DEA) - the units of analysis in this study - were defined by the Brazilian Institute of Geography and Statistics (IBGE) using data from the 2000 Census, in order to publish the data by grouping census sectors, which guarantees statistical and sociological consistency [10]. A total of 19 DEAs are defined for the three municipalities: 14 in Maringá, four in Sarandi, and a single DEA for the entire municipality of Paiçandu.

\subsection{Analytic Strategy}

The percentages of preventable deaths were distributed per DEA, using Local Moran's Index (LISA), which is a distance decay of the global measure of spatial correlation, producing a specific value for each area. This analysis makes it possible to identify and compare the values of each specific DEA to the values of its neighboring DEA - that is, identify DEA clusters with high rates of a given variable and neighboring DEAs with high rates as well (high-high); DEAs with low rates of the variable and neighboring DEAs with low rates (low-low); and transition areas, showing DEAs with low rates and neighboring DEAs with high rates (low-high), or DEAs with high rates and neighboring DEAs with low rates (high-low). Non-significant autocorrelation occurs when the spatial pattern that is different from the whole is not observed [11]. For the analysis of the spatial distribution for preventable infant mortality, the percentages were presented in quartiles, according to the maximum and minimum numbers; greyscales were used in the maps, with the color white representing the lowest and black representing the highest. The research project was analyzed and approved by the Research Ethics Committee of the State University of Maringá, in accordance with CSN Resolution 196/96 (opinion 413/2009) and by the Ethics Committee of the State Secretariat of Health (opinion 120/2009).

\section{RESULTS}

Of the 284 child deaths investigated by the IMPC during the study period and classified according to preventability, $68.7 \%$ were considered preventable, with highlight to DEA 5, represented by the Zones 5 and 6 neighborhoods of Maringá, in which no deaths consid- 
ered preventable took place (Table 1).

Of the 195 deaths classified as preventable, 144 (73.8\%) showed diseases originated in the perinatal period as the underlining cause of death, after investigation. As the second main underlining causes of death as analyzed by the IMPC were external causes, with 22 cases (11.3\%); in third place were diseases of the respiratory system, with $5.1 \%$ of deaths (Table 2).

The spatial distribution of the percentages of preventable deaths shows that, with the exception of the central region of Maringá (DEA 5) and a few surrounding neighborhoods (DEA 4, 1, 2, 3, 6, 7, 8, 12 in Maringá and DEA 17 in Sarandi), most of the maps shows high rates of preventable deaths-between $63.6 \%$ and $84.6 \%$ (Figure 1).

Local Moran's Index showed a concentration of areas with "high-high" correlation at DEA 18 in Sarandi, which features $70 \%$ of preventable child deaths; "low-low" correlation at DEAs 6 and 7, located in central areas of Maringá, with percentages of preventable child deaths of $54.5 \%$ and $50 \%$, respectively; "high-low" correlation at DEA 10 (area with $65.4 \%$ preventable child deaths); "low-high" correlation at DEA 17 in Sarandi (55.6\% preventable deaths) (Figure 2).

\section{DISCUSSION}

The results of this research show that most child deaths that occurred in the municipalities under study (68.7\%) were considered preventable; this means it is essential to seek improvements in prenatal, delivery and newborn assistance, ensuring access by mother and newborn to quality services in a timely manner. The results agree with the findings of a study of municipalities within the $15^{\text {th }}$ Regional Health District of the State of Paraná, between 2000 and 2006, in which 70.1\% of analyzed deaths were considered preventable [2]. In that regard, health and nursing teams must develop actions that meet the challenges created by the conditions of morbi-mortality from preventable causes.

The three municipalities in this study, although located in the interior of Paraná state, are part of a Metropolitan Area officially recognized by state law 83/98, currently consisting of 13 municipalities [10]. Social indicators and the reality of healthcare in the municipalities under study are quite similar to conditions found in the outlying areas of large urban centers, where less favorable socioeconomic conditions are found, such as low income and schooling. This can be confirmed by observing that the

Table 1. Infant mortality by DEA preventability potential. Maringá, Sarandi and Paiçandu, 2004 to 2008.

\begin{tabular}{|c|c|c|c|c|c|c|}
\hline \multirow{2}{*}{ DEA } & \multirow{2}{*}{ Neighborhood } & \multicolumn{2}{|c|}{ Preventable } & \multicolumn{2}{|c|}{ Non-preventable } & \multirow{2}{*}{ Total } \\
\hline & & $\mathbf{N}$ & $\%$ & $\mathbf{n}$ & $\%$ & \\
\hline 1 & Maringá Vila Morangueira & 4 & 57.1 & 3 & 42.9 & 7 \\
\hline 2 & Maringá Jd. Alvorada & 9 & 60.0 & 6 & 40.0 & 15 \\
\hline 3 & Maringá Zona 7 & 3 & 60.0 & 2 & 40.0 & 5 \\
\hline 5 & Maringá Zona 5 and 6 & - & - & 5 & 100.0 & 5 \\
\hline 6 & Maringá Zona 1, 2, 3, 4 & 6 & 54.5 & 5 & 45.5 & 11 \\
\hline 7 & Maringá Av. Mandacaru & 3 & 50.0 & 3 & 50.0 & 6 \\
\hline 8 & Maringá Contorno Norte & 8 & 61.5 & 5 & 31.3 & 13 \\
\hline 10 & Maringá Cidade Alta & 17 & 68.0 & 8 & 32.0 & 25 \\
\hline 11 & Maringá Liberdade-Aeroporto & 16 & 76.2 & 5 & 23.8 & 21 \\
\hline 12 & Maringá Jd. Imperial-Pq Grv. & 12 & 63.2 & 7 & 36.8 & 19 \\
\hline 13 & Maringá Zona Industrial & 6 & 75.0 & 2 & 25.0 & 8 \\
\hline 14 & Maringá Olímpico & 19 & 76.0 & 6 & 24.0 & 25 \\
\hline 15 & Paiçandu & 19 & 73.1 & 7 & 26.9 & 26 \\
\hline 16 & Sarandi Centro & 14 & 77.8 & 4 & 22.2 & 18 \\
\hline 17 & Sarandi Jd. Independência & 5 & 55.6 & 4 & 44.4 & 9 \\
\hline 18 & Sarandi Parque Alvamar & 14 & 70.0 & 6 & 30.0 & 20 \\
\hline 19 & Sarandi Linha do Trem & 22 & 84.6 & 4 & 15.4 & 26 \\
\hline
\end{tabular}


Table 2. Preventable infant deaths according to underlining cause of death. Maringá, Sarandi and Paiçandu, 2004 to 2008.

\begin{tabular}{|c|c|c|}
\hline \multirow[b]{2}{*}{ Underlining causes of death } & \multicolumn{2}{|c|}{ Total } \\
\hline & $\mathbf{N}$ & $\%$ \\
\hline Perinatal & 144 & 73.8 \\
\hline External causes & 22 & 11.3 \\
\hline Respiratory System & 10 & 5.1 \\
\hline Congenital malformations & 8 & 4.1 \\
\hline Diseases of the nervous system & 4 & 2.1 \\
\hline Symptoms, signs and abnormal findings in clinical and laboratory exams, not otherwise classified & 3 & 1.5 \\
\hline Infections and parasites & 2 & 1.0 \\
\hline Endocrinal, nutritional and metabolic & 2 & 1.0 \\
\hline Total (\%) & 195 & 100 \\
\hline
\end{tabular}

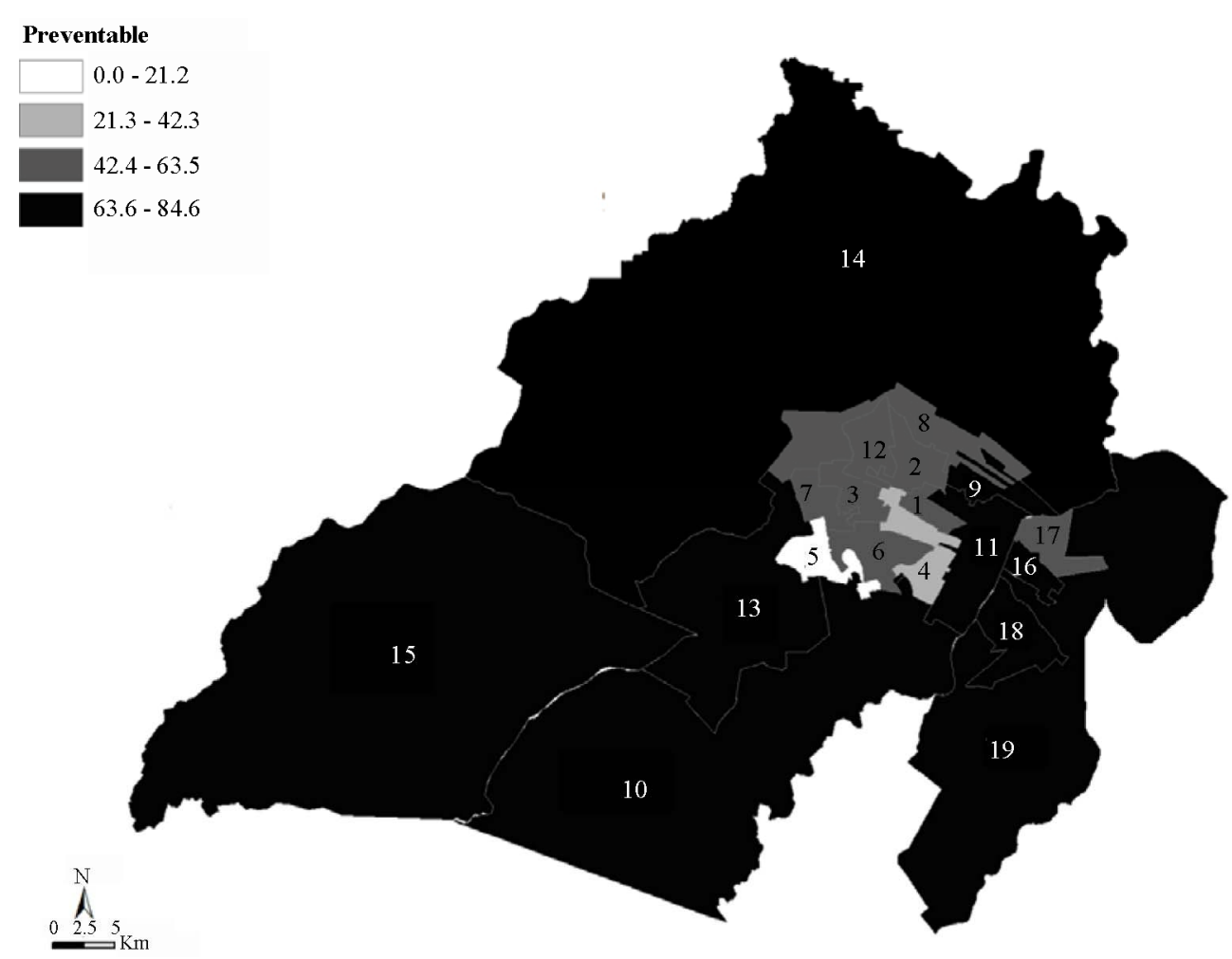

Figure 1. Spatial distribution of the rates of preventable child deaths by DEA in Maringá, Sarandi and Paiçandu, 2004 to 2008.

only region with no potentially preventable child deaths (DEA 5) and another with lower preventability ratesbetween $21.3 \%$ and $42.3 \%$ - (DEA 4) are located in the central area of the city of Maringá (Figure 1). The central area is characterized by residents with high-income occupations and greater schooling-that is, occupations that presuppose specialization and formal education [10]. Also, public services such as clinics and hospitals are located in the central areas of Maringá, facilitating access by residents to these services.

Studies developed to evaluate health inequalities in this same region, using data from SINASC [12,13] showed the municipalities of Sarandi and Paiçandu as vulnerable areas, as they featured higher coefficients of infant mortality and inferior socioeconomic indicators, with higher rates of teenage mothers, mothers with low education, children of black or brown color/race, mothers with insufficient prenatal appointments and newborns with low vitality scores at birth. These results indicated vulnerable areas that coincide with the areas with higher preventability percentages found in the present study.

Recognizing the health inequalities combined with a discussion on the territorialization of preventable child deaths and the underlining causes of preventable deaths 


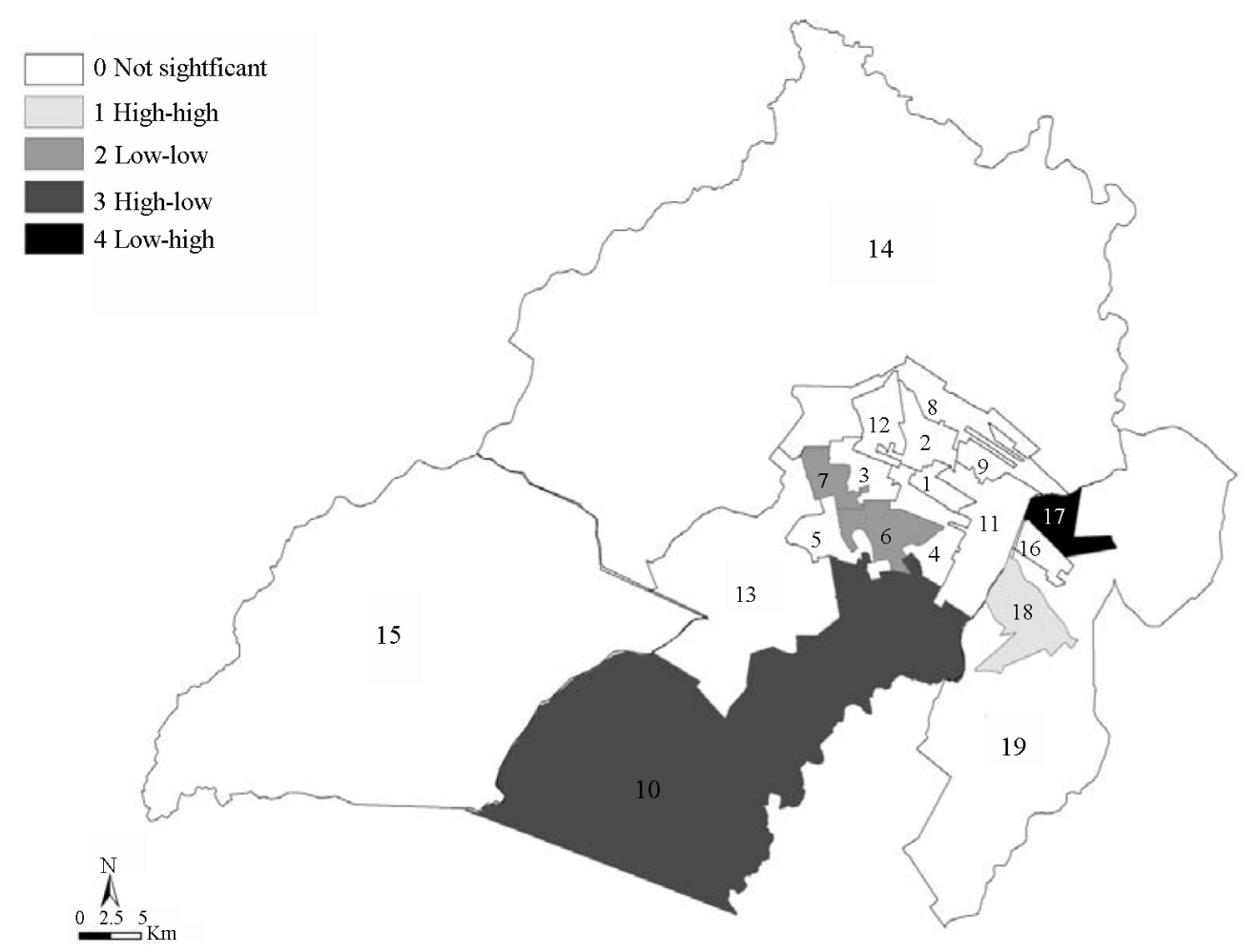

Figure 2. Spatial distribution of the percentages of preventable child deaths by Local Moran's Index (LISA) and DEA in Maringá, Sarandi and Paiçandu, 2004 to 2008.

in the municipalities of this study can contribute to an understanding of infant mortality, limits and possibilities of health actions [14], and can provide health professionals with awareness of the existing inequality among the different regions of the municipalities.

Although the studied municipalities have lower infant mortality coefficients when compared to other municipalities in different regions of Brazil (9.5, 14.3 and 11.3 deaths per thousand live births in Maringá, Sarandi and Paiçandu, respectively, between 2004 and 2008), adequate prenatal measures and care measures during delivery and neonatal stages, such as improving service and organization and arranging services in networks, would represent 195 child deaths that could be prevented during the study period, as these deaths were classified as preventable according to an analysis by the IMPC.

With regard to the underlining causes, there were a high percentage of deaths resulting from conditions originating during the perinatal period, from diseases of the respiratory system and from external causes, which combined for $90.2 \%$ of deaths. These results revealed the potential preventability of these deaths, as perinatal causes represent fully or partially "preventable deaths" if adequate care measures were implemented for the mother during gestation and delivery, and to the newborn [15].

It is known that childhood is a particularly vulnerable life stage, in which biological determinants of morbimortality are strongly linked to external conditionseither socioeconomic or environmental (housing, diet, sanitation, hygiene and family relations) - or to the availability of health services [16]. We must also consider the influence of public health measures; even if low-cost or easily implementable, these measures are responsible for a considerable reduction in infant mortality [17]. Therefore, partnerships with other sectors of society-such as the Children's Ministry, for instancedemonstrate that integration must be considered between all social levels and public/private partnerships in order to solve problems that transcend the field of clinical practice, as in the case of social inequalities [18].

In the present work, the analysis of preventable child deaths showed areas with "high-high" correlation at DEA 18 , in the Sarandi region, meaning that it is an area with a high rate of preventable deaths surrounded by other regions with high percentages as well. "Low-low" correlations in the central areas of Maringá showed homogenous area in that region, with lower percentages of child death preventability. "High-low" correlations in the outlying areas of Maringá showed an area that needs to be better evaluated, as it showed percentages that contrast with the results found in the neighboring DEAs of that municipality.

The "low-high" correlation for the central area of 
Sarandi shows that even within that municipality, there is a pattern characterized by a nucleus-periphery distribution, with better health indicators for residents of the city's central areas. The results indicate that although all three municipalities show DEAs with high percentages of preventable infant mortality, Sarandi has the highest values. That observation can be partially explained by the spatial occupation of Sarandi, which has been characterized by people who wish to live in Maringá but move to neighboring municipalities in search of more affordable housing, yet maintain their employment, underemployment, studies, shopping and leisure in the other municipality [10]. Therefore, conditions acknowledged as risks to the mother and newborn — which can be prevented and intervened by the health sector-combined with unfavorable socioeconomic conditions such as low family income and low education-can characterize iniquity. Knowing these factors, the responsibility of managers, health professionals and services is directly linked to preventable child deaths $[19,20]$.

The results of this study may show biases characteristic of research studies that use secondary databases, either in quantity or quality of data, as the information is subject to data accuracy and thoroughness, which do not invalidate their use. Information systems with the data routinely collected in health services constitute valuable sources of information, the results of which can contribute to improved quality and coverage of this information when analyzed. However, we must emphasize the importance of participation and responsibility of municipalities for producing, organizing and feeding the databases. It is necessary to eliminate errors in records in order to obtain reliable data, including address information-essential in studies that use georeferenced cartographic parameters [21,22]. In addition to collecting and forwarding the data, the municipalities must monitor and evaluate the quality of the data in health information systems, by continuously training the agents responsible for that activity [21].

By using geoprocessing techniques, this analysis adds information on preventable infant mortality, given that the location of the event in geographic space was possible using thematic maps. Using homogenous areas, such as DEAs, to monitor health events can contribute so that managers can evaluate each area differently. The results showed that for the municipalities under analysis, outlying DEAs feature the highest rates of preventable child deaths. This conclusion leads to the consideration that these populations are more susceptible to hardship in accessing medical technologies and adequate health services, which would be enough to prevent infant morbimortality.

Another contribution of this study to the territorialbased analysis of the distribution of potentially prevent- able deaths and their underlying causes is the use of data generated from the death investigation analyses by the IMPCs working in the Regional Health Districts of the State of Paraná. The analysis of child death preventability can assist in identifying the areas with the highest probability of success or failure in preventing these deaths, in addition to indicating the performance of the healthcare system and the population's behavior when seeking healthcare. This methodology of study can be reproduced in other localities at different desired units of analysis. The present study used homogenous areas as standardized by IBGE according to the National Census, which guarantees the quality of the methodology.

It is worth underlining that even though DEAs represent smaller areas within a municipality, with more homogenous characteristics, they can still hide different situations and realities to be explored.

It is important to highlight the limits of interpretation of the results of this study, in that the information is subject to the thoroughness and accuracy of the data regarding the addresses of the mothers of each newborn. This may compromise the analysis and monitoring of preventable infant mortality in the geographic realm.

Other studies are still required in order to better know the population residing in the regions with the highest rates of preventability, evaluating the conditions of access to health services, quality of service, as well as reference and counter-reference services in caring for women during gestation and delivery and for newborns.

Lastly, the debate on the responsibility for preventable child death must be taken to health services and incorporated in the work routine, as the occurrence of preventable child death may indicate the need for revision and suitability of health assistance to the population in their numerous health needs, beyond those related to mother and child.

\section{REFERENCES}

[1] Ministry of Health (BR) (2009) Departamento de ações programáticas estratégicas. Manual de vigilância do óbito infantil e fetal e do comitê de prevenção do óbito infantil e fetal. MS, Brasília.

[2] Mathias, T.A.F., Assunção, A.M. and Silva, G.F. (2008) Infant deaths investigated by the Prevention Committee of Infant Mortality in region of Paraná state. Revista da Escola de Enfermagem, 42, 445-453. http://dx.doi.org/10.1590/S0080-62342008000300005

[3] Malta, D.C., Duarte, E.C., Escalante, J.J., Almeida, M.F., Sardinha, L.M.V., Macário, E.M., et al. (2010) Avoidable causes of infant mortality in Brazil, 1997-2006: Contributions to performance evaluation of the Unified National Health System. Cadernos de Saúde Pública, 26, 481-491. http://dx.doi.org/10.1590/S0102-311X2010000300006

[4] Rutstein, D.D., Bereberg, W., Chalmers, T.C., Child, C.G., 
Fishman, A.P., Perrin, E.B., et al. (1976) Measuring the quality of medical care: A clinical method. The New England Journal of Medicine, 294, 582-588. http://dx.doi.org/10.1056/NEJM197603112941104

[5] Ministry of Health (BR) (2011) Departamento de informática do SUS. DATASUS, MS, Brasília.

[6] Vianna, R.C.X.F., Moro, C.M.C.B., Moysés, S.J., Carvalho, D. and Nievola, J.C. (2010) Data mining and characteristics of infant mortality. Cadernos de Saúde Pública, 26, 535-542.

http://dx.doi.org/10.1590/S0102-311X2010000300011

[7] Barcellos, C., Ramalho, W.M., Gracie, R., Magalhães, M.A.F.M., Fontes, M.P. and Skaba, D. (2008) Geocoding health data in sub-municipal scale: Some Brazilian experiences. Epidemiologia e Serviços de Saúde, 17, 59-70.

[8] Hau, L.C., Nascimento, L.F.C. and Tomazini, J.E. (2009) Geoprocessing to identify the pattern of birth profile in Vale do Paraíba. Revista Brasileira de Ginecologia e Obstetrícia, 31, 171-176.

[9] Ipardes (2011) Caderno estatístico. Município de Maringá. http://www.ipardes.gov.br/modules/conteudo/conteudo.ph p?conteudo=5

[10] Santana, R.G., Udo, M.C.T., Previdelli, I.T.S. and Rodrigues, A.L. (2010) Análise da ocupação residencial na Região Metropolitana de Maringá: A construção e aplicação de uma tipologia. In: Rodrigues, A.L., Tonella, C. and Organizadores, Eds., Retratos da Região Metropolitana de Maringá: Subsídios para a Elaboração de Políticas Públicas Participativas. Eduem, Maringá, 17-39.

[11] Anselin, L. (1994) Local indicators of spatial association -LISA. Regional Research Institute, West Virginia University, Virginia.

[12] Predebon, K.M., Mathias, T.A.F., Aidar, T. and Rodrigues, A.L. (2010) Socio-spatial inequality expressed by indicators from the Information System on Live Births (SINASC). Cadernos de Saúde Pública, 26, 1583-1594. http://dx.doi.org/10.1590/S0102-311X2010000800012

[13] Oliveira, R.R., Costa, J.R. and Mathias, T.A.F. (2012) Spatial distribution and autocorrelation of infant mortality for three cities in Paraná state, Brazil. Geospatial Health, 6, 257-262.

[14] Ventura, R.N., Oliveira, E.M., Silva, E.M., Silva, N.N. and Puccini, R.F. (2008) Living conditions and infant mortality in the municipality of Embu, São Paulo, Brazil. Revista Paulista de Pediatria, 26, 251-257. http://dx.doi.org/10.1590/S0103-05822008000300009

[15] Malta, D.C. and Duarte, E.C. (2007) Causes of avoidable mortality through effective healthcare services: A review of the literature. Ciência \& Saúde Coletiva, 3, 765-776. http://dx.doi.org/10.1590/S1413-81232007000300027

[16] Victora, C.G., Aquino, E.M.L., Leal, M.C., Monteiro, C.A., Barros, F.C. and Szwarcwald, C.L. (2011) Saúde de mães e crianças no Brasil: Progressos e desafios. The Lancet, 6736, 32-46.

[17] Silva, L.R., Christoffel, M.M. and Souza, K.V. (2005) History, conquests and perspectives of the woman and child care. Texto Contexto-Enferm, 14, 585-593. http://dx.doi.org/10.1590/S0104-07072005000400016

[18] Silva, A.C.M.A., Villar, M.A.M., Wuillaume, S.M. and Cardoso, M.H.C.A. (2009) Opinions by physicians from the Family Health Program on four health care priorities proposed by the agenda for commitment to comprehendsive child health and reduction of infant mortality. Cadernos de Saúde Pública, 25, 349-358. http://dx.doi.org/10.1590/S0102-311X2009000200013

[19] Vilela, M.B.R., Bonfim, C. and Medeiros, Z. (2008) Infant mortality due to infectious and parasitic diseases: A reflection of the social inequalities in a municipality in the Northeast Region of Brazil. Revista Brasileira de Saúde Materno Infantil, 8, 445-461.

[20] Barros, F.C. and Victora, C.G. (2008) Maternal-child health in Pelotas, Rio Grande do Sul State, Brazil: Major conclusions from comparisons of the 1982, 1993, and 2004 birth cohorts. Cadernos de Saúde Pública, 24, S461S467. http://dx.doi.org/10.1590/S0102-311X2008001500012

[21] Moilmaz, S.A.S., Garbin, C.A.S., Garbin, A.J.I., Zina, L.G., Yarid, S.D. and Francisco, K.M.S. (2010) Prenatal information system: Critical analysis of register in a municipality of São Paulo State. Revista Brasileira de Enfermagem, 63, 385-390.

[22] Grady, S.C. and Enander, H. (2009) Geographic analysis of low birthweight and infant mortality in Michigan using automated zoning methodology. International Journal of Health Geographics, 18, 8-10. 